\title{
Evaluation of the Energy Consumption of Recycling Process
}

\author{
Toshiharu Goto \\ Shizuoka University \\ Japan
}

\section{Introduction}

Human activities have always consumed energy. In ancient times, human beings started cultivation to increase the amount of energy taken in via food consumption, as a result, humans had time to invent culture and technology. That is to say, the surplus of energy made for an affluent society. This trend was dramatically accelerated by the Industrial Revolution. This era initiated the consumption of fossil fuels in every aspect of our life, even in cultivation. This means that our life is supported by energy consumption.

Fossil fuels are formed from dead, buried organisms and it takes millions of years to generate fossil fuels, meaning that our consumption rate is too fast as a sustainable energy resource. One of the discussions about this issue was written by the Club of Rome (Meadows et al., 1972). Evaluation of the technology from the perspective of energy consumption is one of the most important discussions within engineering.

Because fossil fuels are limited, the amount of energy which we can use will have to peak at some point (Hubbert, 1956). Predicted oil peaks range between 2010 and 2040 according to the review by Richard (Kerr, 2007). The International Energy Agency (IEA) reports in the World Energy Outlook 2010 that the peak of conventional oil came on 2007. On the other hand, rapid economic growth of developing nations means that global demand for energy is growing. These situations indicate that the energy issue will become more serious in the near future. So, reduce, reuse and recycling ( $\left.3 R^{\prime} s\right)$ are more and more important for the resource problem.

Supercritical fluid (SCF) is expected to be one of the technologies used for the recycling of plastics because of its reactivity. On the other hand, there are general discussions on the energy consumption of the recycling of plastics, which indicate that the recycling can be wasteful of energy in some cases (Takeda, 2008). If much more energy is consumed for recycling than to make virgin material, recycling cannot save resources. This is especially the case when using SCF; energy consumption should be considered because large amounts of supercritical water or methanol require large amounts of energy. A phase diagram of methanol is shown in Fig. 1. It indicates that with SCF, the temperature and the pressure of the materials are higher than critical points. Critical points of water and methanol are shown in Table 1. Critical temperatures of the alcohol and water are higher than $250^{\circ} \mathrm{C}$. Figure 2 shows the internal energy of methanol (Reuck \& Craven, 1993) which increases with temperature at $10 \mathrm{MPa}$, which means that making such a high temperature and pressure state requires large amounts of energy. 
Pressure

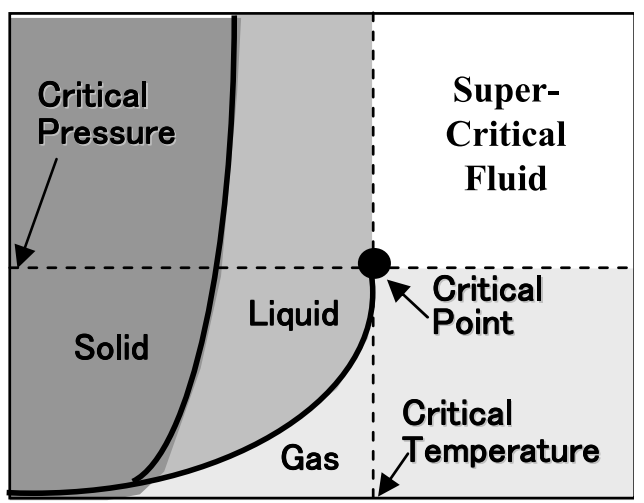

Temperature

Fig. 1 Schematic phase diagram

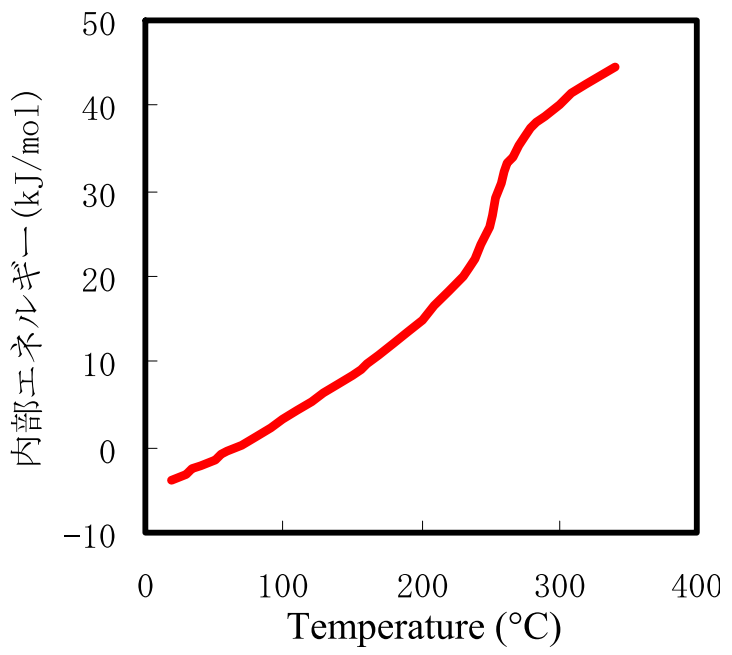

Fig. 2 Internal energy of methanol at $10 \mathrm{MPa}$

\begin{tabular}{lll}
\hline Material & Methanol & Water \\
\hline Temperature $\left({ }^{\circ} \mathbf{C}\right)$ & 240 & 374 \\
Pressure $(\mathrm{MPa})$ & 8.0 & 21.8 \\
\hline
\end{tabular}

Table 1. Critical points

So, a technology which can minimize the amount of SCF was required for the recycling process using SCF to avoid wasting energy. 
It was reported that the extruder can be used as a feeder and a reactor for the supercritical alcohol (Goto et al., 2005). Supercritical fluid can be injected into the polymer because the extruder can pressurize the polymer, which means that such process can minimize the amount of supercritical fluid and energy consumption. Here, LCA (Life Cycle Assessment) and EPR (Energy Profit Ratio or EROI:Energy Return on Investment) is applied to evaluate the energy consumption of this technology.

General knowledge of the LCA and SCF was explained first. Then, chemical reaction for the recycling of Si-XLPE in the supercritical methanol (Goto et al., 2008; Goto et al., 2001) was shown. After that, the technology which uses the extruder for the chemical reaction in supercritical fluid to develop the continuous process for industrialization (Goto et al., 2011) was introduced. The obtained recycled PE properties satisfied the requirements of Japan's industrial standard of insulation for $600 \mathrm{~V}$ cross-linked polyethylene cable (600V XLPE cable) (Goto et al., 2006). Then energy consumption to make recycled PE is compared with that of virgin PE by LCA as one example of the evaluation of energy consumption for recycling technology.

\section{Life Cycle Assessment (LCA) for evaluation of recycling technology}

The final aim of LCA is the evaluation of the influence of human activity on the environment and society to select the best combination of products, services or technology. So, it is useful for the development of technology to take an objective view. LCA is quantitative analysis from raw material extraction through to processing, distribution, use, maintenance, recycling and disposal (Ito et al., 2007). It is useful for engineers, who tend to take the seeds oriented approach, to take a wider view of the technology. The procedure is standardized by ISO 14040 and 14044 in four distinct phases as follows:

\section{Goal and Scope}

It is impossible to gather all of information which is required for LCA. It is required to consider which raw materials and process of works affect the goal, to determine the boundaries of investigation. In this phase, function unit, system boundaries, assumptions, the allocation methods are defined.

\section{LCI}

Next, the scenario of life cycle is assumed from and to nature system. The data which cannot be directly measured can be compensated for by the database of unit base for LCA.

\section{LCIA}

The effect of the obtained results are discussed with regard to the goal and scope, such as effect on global warming, acid rain or resource problem. Normalization by weighting is conducted depending on goal and scope. But weighting will also make the meaning of the obtained data obscure in some cases. So, when it comes to studying energy consumption, it is preferable not to use weighting.

4. Interpretation

The key purpose of this phase is checking the credibility and accuracy of data, and sensitivity of parameters. It is also evaluated if the goal and scope is achieved. 


\section{Energy Profit Ratio (EPR)}

The concept of energy profit ratio is one of the methods for the interpretation of the results of LCA. EPR originates from the idea of the 'rabbit limit' which is based on the case of rabbit hunting shown in Figure 3 (Gunther).

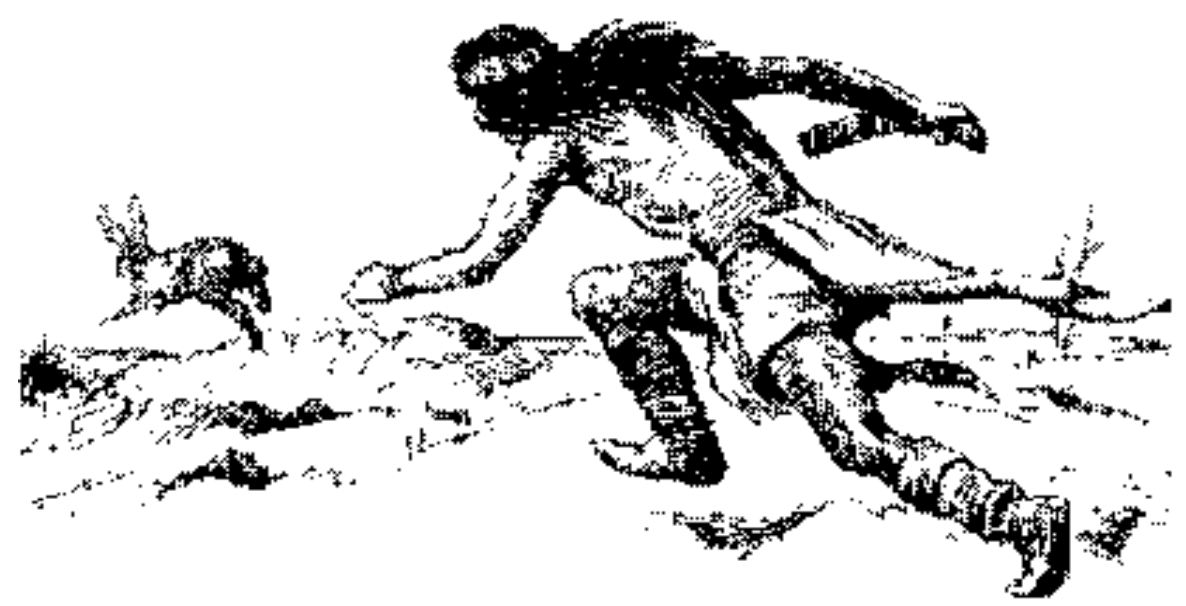

Fig. 3. Rabbit hunting

When you have to chase a rabbit to obtain food, you need to consume energy for hunting. If the energy taken for hunting the rabbit is greater than that of the energy obtainable from eating the rabbit, rabbit hunting is not sustainable. EPR is determined using the following equation (Amano, 2008):

$$
\text { EPR }=\text { yielded energy / consumed energy }
$$

EPR must be more than 1 if the activity is sustainable. The larger the amount of EPR means the greater the efficiency of the energy resource. So, EPR is also convenient for consideration of sustainatbility. This method was originally used to evaluate the value of energy resource such as oil, coal and so on. Here, we adopt the concept of EPR for recycling. The final aim of the recycling technology is to contribute to the sustainability of human life, that is to say, evaluation of recycling technology requires the concept of the rabbit limit. In the case of recycling, it must be evaluated if consumption of energy decreases. Here, energy consumption ratio (ECR) is defined as follows (Goto et al., 2009):

ECR $=$ Consumed energy for virgin product / Consumed energy for recycled products

In this case, it is assumed that the recycled product is as valuable as the virgin product, such as in the case of horizontal recycling. This concept can also be adopted in the case of the improvement of industrial processes, distribution of products or supply chain to compare before and after improvement. 


\section{Supercritical fluid for recycling of plastics}

A comparison of properties between gas, liquid and SCF is shown in Table 2. The density of SCF is $1 / 10-1 / 2$ of liquid. On the contrary, viscosity close to the gas and diffusion constant is in the middle of gas and liquid. As a result, SCF has strong chemical activity. So, SCF is expected to be the method for decomposition of harmful chemical materials (Sako et al., 1998). Moreover, dielectric constant decreases around the critical point, which means that the properties as solvent are change around critical points (Saito, S.,1996). For example, water can be mixed with oil above the critical point of water.

When you need to use the reaction between water and polymer which is not dissolved in water, supercritical water can be used without other solvents. Another merit of using supercritical fluid is the ability of diffusion. Cross-linked polymers are difficult to stir to accelerate the chemical reaction because cross-linking of polymers robs the liquidity of polymer. The high diffusion constant of SCF is positive effect for water or methanol to diffuse into the polymer without stirring. All these properties lead us to expect that SCF has advantages for the chemical recycling of cross-linked polymers.

\begin{tabular}{|l|l|l|l|}
\hline Properties & Gass & Supercritical fluid & Liquid \\
\hline Density $\left(\mathrm{kg} / \mathrm{m}^{3}\right)$ & $0.6 \sim 1$ & $200 \sim 900$ & 1000 \\
\hline Diffusion Constant $\left(\mathrm{m}^{2} / \mathrm{s}\right)$ & $10^{-5}$ & $10^{-7} \sim 10^{-8}$ & $10^{-9}$ \\
\hline Viscosity $(\mathrm{Pa} \cdot \mathrm{s})$ & $10^{-5}$ & $10^{-5} \sim 10^{-4}$ & $<10^{-3}$ \\
\hline
\end{tabular}

Table 2. Properties of supercritical fluid, liquid and gas

\section{Application of chemical reaction in supercritical fluid}

Here, a general analysis of chemical reaction in supercritical fluid is given. Chemical reaction in SCF is basically the same as chemical reaction at room temperature. SCF is useful if you need to accelerate the chemical reaction kinetics. Most of the research of chemical reaction of supercritical water and alcohol is transesterification. For example, decomposition of carbonate (Arai, 2002), and also applied for the siloxane bond such as decomposition of silica gel (Kitahara, 1969; Kitahara et al., 1970) or silicon rubber. All of this research takes advantage of acceleration of chemical reaction in supercritical fluid.

On the other hand, the disadvantages of SCF are difficulties in the development of the process for commercialization because it is difficult to put solid material into the SCF and take materials from the SCF. This difficulty is mainly derived from the properties of SCF which is close to the highly pressurised gas. So, development of a continuous process for SCF is discussed in the following section.

\section{Recycling technology for Si-XLPE using supercritical fluid}

Silane cross-linked polyethylene (silane-XLPE) is widely used as an insulation material for wires and cables (Maruyama, 2003). Recycling of cross-linked polymers poses one of the most difficult problems in the recycling of polymer wastes. Most of industrial waste silaneXLPE is buried in landfills or burned as fuel, because silane-XLPE is difficult to process due to its low fluidity derived by cross-linking elements formed by the siloxane bond. The research for recycling of silane-XLPE as polymer is as follows: 
1. Clashed XLPE pellet is mixed with virgin polyethylene using a twin screw extruder (Tokuda et al., 2003),

2. Powdered XLPE is used as a filler of polymer (White, et al., 2000; Voldner, 2000).

These technologies require further investigation of the application for recycled products and the development of the market due to the apparent difficulty in using directly the recycled product as insulation of wire or cables (horizontal recycling).

\subsection{Chemical reaction for recycling of Si-XLPE}

Chemical reaction in supercritical alcohol is shown in Figure 4. Siloxane bond (Si-O-Si) can be decomposed into the alkoxide group (-OR) or the hydroxyl group (-OH) by supercritical alcohol selectively.

The condition for selective decomposition of cross-linking bond is investigated. The gel fraction and molecular weight of products against decomposition temperature is shown in Figure 5. The gel fraction vanished at over $300^{\circ} \mathrm{C}$ when methanol was used as supercritical fluid. Using water, a temperature over $370^{\circ} \mathrm{C}$ was necessary to decline the gel components to 0wt $\%$. These results indicate that the cross-linking element was completely decomposed at over $300^{\circ} \mathrm{C}$ using methanol and at $370^{\circ} \mathrm{C}$ using water. Molecular weight was decreasing at over $340^{\circ} \mathrm{C}$ using water and methanol. This result agreed with the general knowledge about the thermal decomposition temperature of PE.

By using water, the molecular weight of the products would be lower than raw PE whenever the gel fraction of the products decreased to $0 \%$. It is indicated that the reaction in supercritical water was not selective only for the cross-linking element, but also for the main chain of PE.

In the case of methanol, at temperatures between $300^{\circ} \mathrm{C}-340^{\circ} \mathrm{C}$ and pressure more than critical pressure, the cross-linking element was completely decomposed and the molecular weight of the recycled PE was kept the same as virgin PE before being cross-linked. It means that using supercritical methanol is necessary to obtain thermoplastic PE which has the same molecular weight as virgin PE.

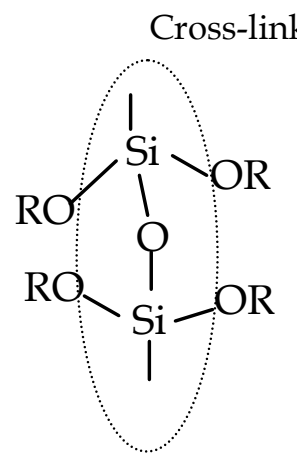

Silane-XLPE<smiles>[R]O[Si]([R20])([R20])[R]([R20])([R2])[R]</smiles>

Recycled PE

Fig. 4. Chemical reaction of crosslinking bond in supercritical alcohol 


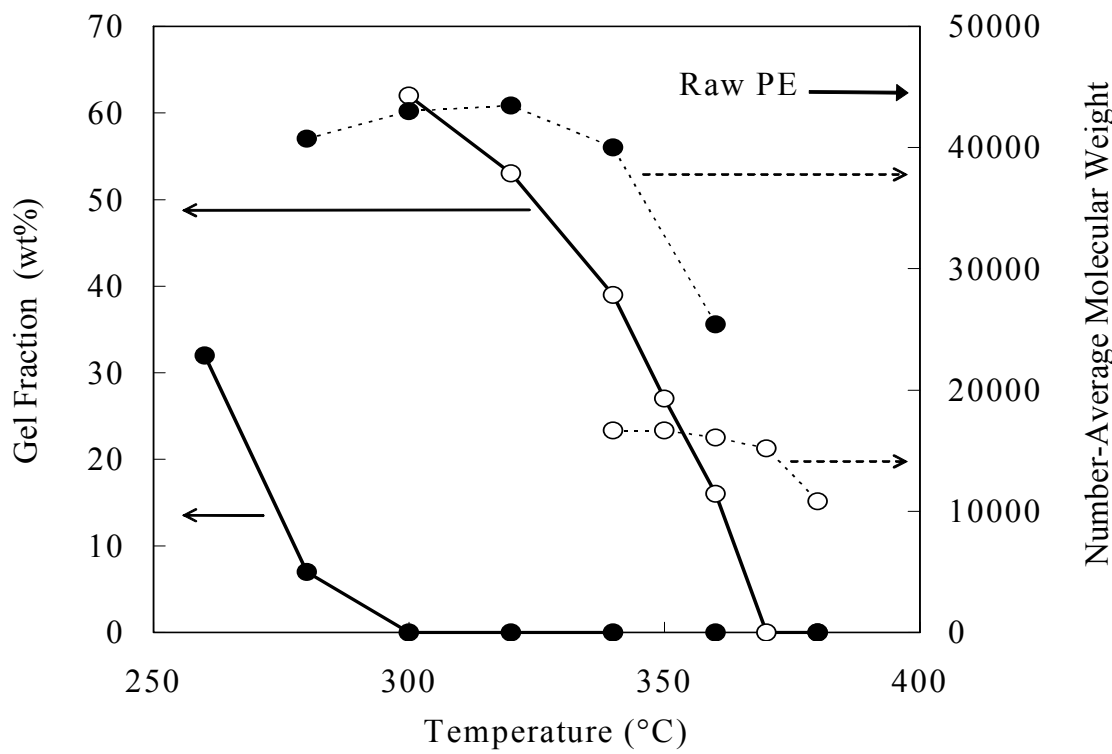

Fig. 5. Gel fraction and number molecular weight of recycled product made by supercritical methanol and water. Black circle:made by methanol, White circle: made by water

\subsection{Process design}

One of the most important issues with supercritical fluid technology is the development of a continuous industrial process for the solid material. The conventional process for SCF is compared with the process using an extruder that is developed for the recycling of crosslinking polyethylene in Table 3. The most fundamental method is the batch process, but in using this process, the reactor should be cooled to take out the product and put raw materials in the reactor. That is to say, efficiency of heat energy is low. In the case of a semicontinuous process, heat efficiency is better than that of the batch process, but the amount of water or alcohol required is about the same as the batch process because the pressure is applied by the materials used as SCF. The amount of SCF cannot be saved in this process, which means improvement on the efficiency of energy is small. In the general continuous process for the supercritical fluid, the solid material was crushed into small particles and dispersed in the solvent to make a slurry. Then, a liquid pump was used to feed the slurry, but this kind of process also has a problem for industrialization as follows. It is very expensive to crush the materials into particles to make powder for slurry. Moreover, the process requires much more solvent than the solid material itself. Ordinary, 10 of solvent required for one of solid material to make slurry. To solve these problems, we developed a new continuous process for the supercritical fluid using an extruder. Extruder is used as the processing machine for polymers. Pressure and heat can be applied to the polymer at $400^{\circ} \mathrm{C}$ and $50 \mathrm{MPa}$ with the extruder. The polyethylene which is crushed into $5 \mathrm{~mm}$ in diameter can be fed to extruder. This means that the new process using extruder does not require making powder of solid material. Furthermore, a minimum amount of supercritical fluid is required for the chemical reaction into pressurized polymer. 


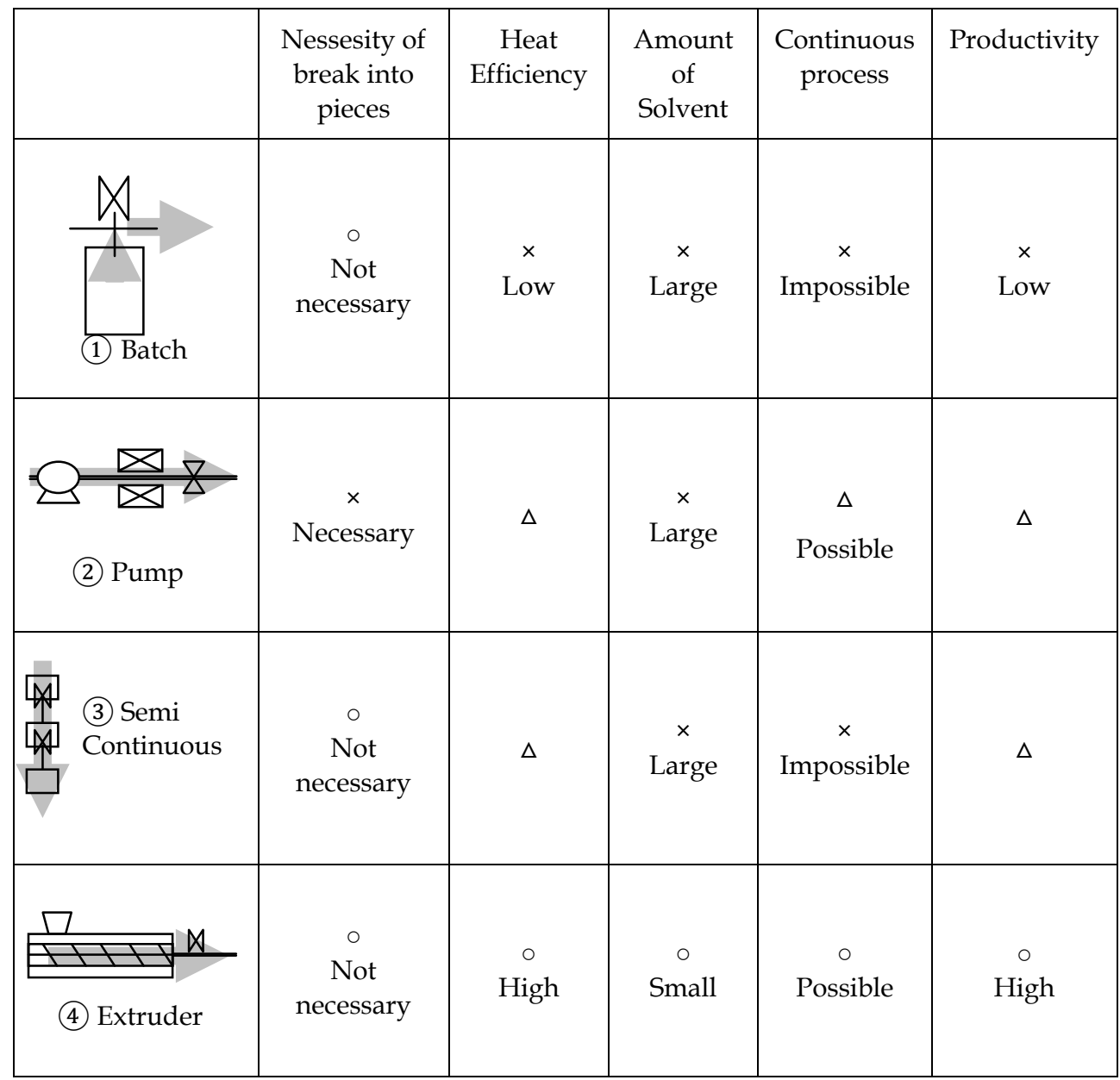

Table 3. Comparison of the process for supercriticalfluid

The process was designed to make recycled PE from crushed Si-XLPE waste continuously and automatically. A scheme of the continuous process is shown in Figure 6 . The twin screw extruders are made by Japan Steel Works and were used as equipment for the chemical reaction (Ext-Chem) and degassing (Ext-Degas). Methanol was fed using a high pressure pump from the methanol tank and heated to supercritical state by the heater before it was injected to the Ext-Chem. The tubular reactor was attached to the Ext-Chem to keep Si-XLPE and methanol for more than $15 \mathrm{~min}$ at $10 \mathrm{MPa}, 335^{\circ} \mathrm{C}$. The pressure control valve was connected to the tubular reactor. Ext-Degas was mounted to the outlet of the pressure control valve to separate the recycled PE and the gas. Pelletizer was prepared to cut the recycled PE strand into the pellets. The whole electric power demand for this process was measured using the attached ammeter to evaluate the energy consumption. 


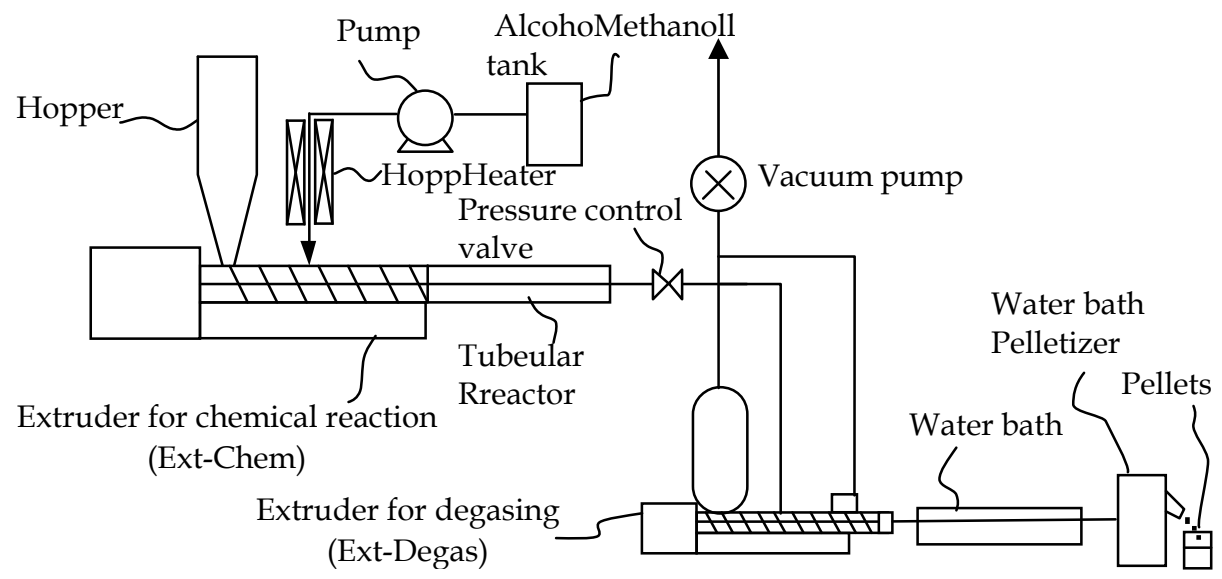

Fig. 6. Schematic diagram of the continuous process for recycling of silane-XLPE by supercritical alcohol using twin screw extruders.eCa SE

The Si-XLPE pellet with 30\% in the degree of gel fraction was gathered from the factory for the production of $600 \mathrm{~V}$ XLPE cable. The methanol used here was made by WAKO Chemicals.

$40 \mathrm{~kg} /$ hour of Si-XLPE was charged to the extruder from the hopper, then $10 \mathrm{phr}$ of alcohol was injected to the Ext-Chem. The injected supercritical alcohol was kept at over $300^{\circ} \mathrm{C}$ at 10 $\mathrm{MPa}$. The reactor was kept at $330^{\circ} \mathrm{C}$ and $10 \mathrm{MPa}$. The Ext-Degas was set at $200^{\circ} \mathrm{C}$ to extrude the recycled $\mathrm{PE}$.

Electric power demand for this process is shown in Figure 7. Power demand is stable at around $160 \mathrm{~A} 200 \mathrm{~V}$ in 10 hours, which means that the process was well controlled. The average electric power demand in 10 hours is $159.3 \mathrm{~A}, 200 \mathrm{~V}$.

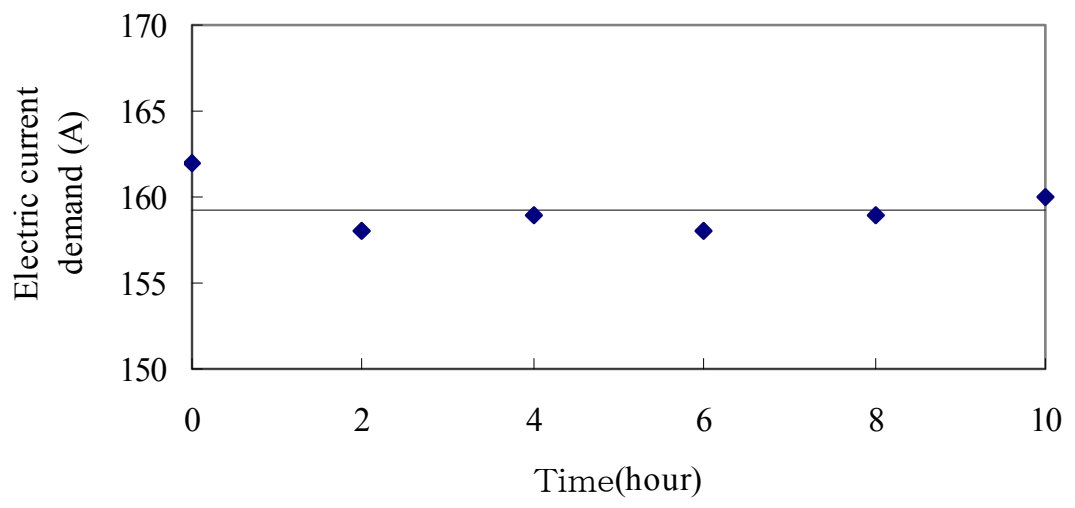

Fig. 7. Electric power demand for the recycling. 


\subsection{Properties of the productst}

The appearance of cable extrusion of the recycled PE and the $600 \mathrm{~V}$ rating XLPE cable (cross section of conductor $38 \mathrm{~mm} 2$, thickness of insulation:1.2mm) is shown in Figure 8 . The proccessability of the recycled PE was good enough to be used as cable insulation.


(a) Cable extrusion
(b) Recycled 600V rating XLPE cable

Fig. 8. Trial for cable recycling

The properties of the recycled cable are shown in Table 4. The initial mechanical and electrical properties of the cable satisfied JIS C 3605.

\begin{tabular}{lll}
\hline Items & Recycled Cable & Required \\
\hline Tensile Strength at break(MPa) & 20 & $>10$ \\
\hline Elongation $(\%)$ & 500 & $>200$ \\
\hline Volume Resistance $(\mathrm{M} \Omega / \mathrm{km})$ & $10 \times 10^{5}$ & $>1.5 \times 10^{3}$ \\
\hline Breakdown Voltage $(\mathrm{kV})$ & 28 & - \\
\hline Heat Deformation $(\%)^{*}$ & 0.9 & $<40$ \\
\hline
\end{tabular}

*: At $120^{\circ} \mathrm{C}$ under the force of $20 \mathrm{~N}$

Table 4. Properties of the recycled cable

\section{Life cycle assessment of recycling of silane-XLPE}

$600 \mathrm{~V}$ XLPE cable is the target application of this technology. The structure of 600V XLPE cable is shown in Figure 9. The conductor is covered by insulation and sheath.

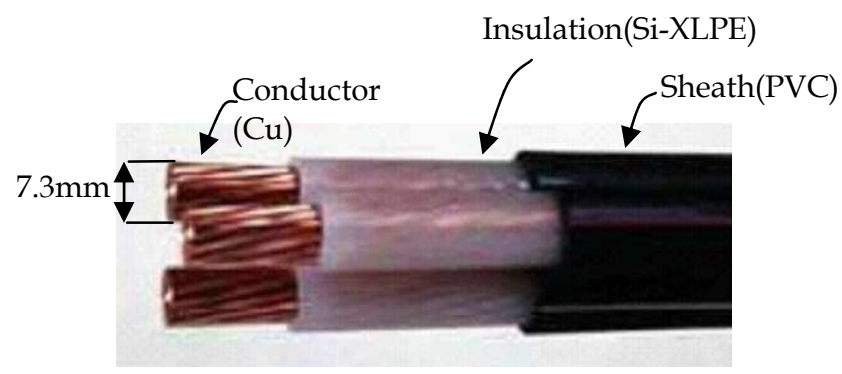

Fig. 9. Structure of 600V XLPE cable. 
Figures 10 and 11 illustrate the process for production of 600V XLPE cable using virgin PE and recycled $\mathrm{PE}$ as insulation respectively. The same copper $(\mathrm{Cu})$ and polyvinyl chloride (PVC) can be applied to the virgin and the recycled product as the conductor and sheath respectively.

It is reported that recycled PE can be used the same as the virgin PE (Goto et al., 2006), which means that energy used for the cable processing should be the same in each product. So, the system boundary was determined as the hatched box in Figures 10 and 11. Energy consumption to produce the recycled PE was compared with that of the virgin PE in this study. The life cycle energy assessment of the whole process for the production of cable is reported in another paper (Goto, 2004).

Materials

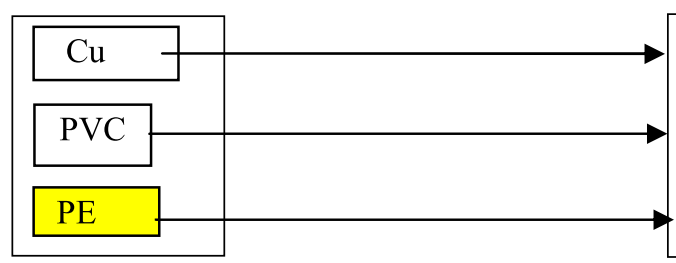

Cable processing

Twist cupper wire, Extrude PE and PVC, Twist cable
Products

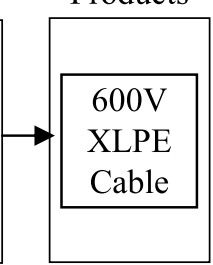

Fig. 10. Process for the the virgin products.

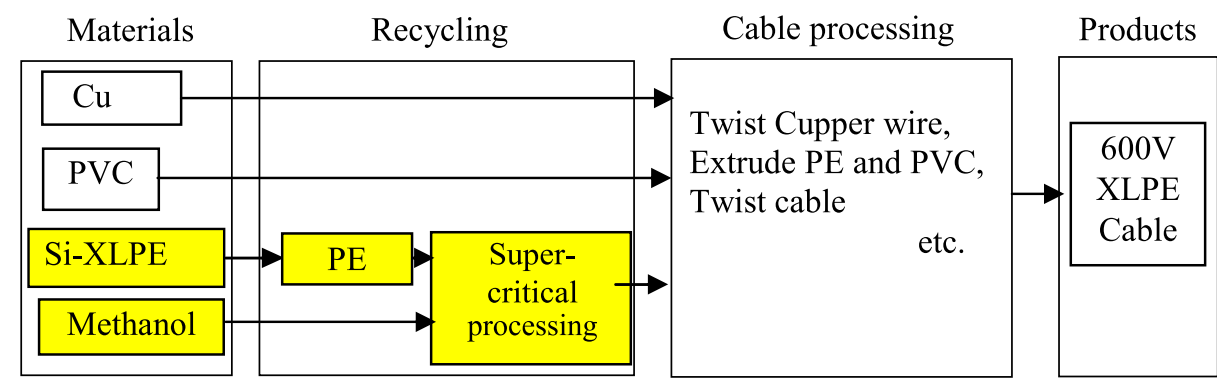

Fig. 11. Process for the recycling products.

Si-XLPE was assumed to be gathered from the cable factory and recycled at that site. Energy unit bases of virgin PE, methanol, electric power and steel were represented in Table 5 (Amano, 2006). These values were converted to the energy per $1 \mathrm{~kg}$ of PE for calculation.

\begin{tabular}{|l|l|l|}
\hline & Parameters & Unit base \\
\hline PE & $U_{P E}$ & $7054 \mathrm{kcal} / \mathrm{kg}$ \\
\hline Methanol & $U_{M e O H}$ & $5431 \mathrm{kcal} / \mathrm{kg}$ \\
\hline Electric power & $U_{e l e}$ & $2250 \mathrm{kcal} / \mathrm{kWh}$ \\
\hline Steel & $U_{F e}$ & $6125 \mathrm{kcal} / \mathrm{kg}$ \\
\hline
\end{tabular}

Table 5. Energy unit base

Energy for the recycled PE (Er)was represented as following equation. 


$$
E_{r}=U_{\mathrm{MeOH}}+E_{1}+E_{2}
$$

$E_{1}$ and $E_{2}$ are the energy consumption for crushing Si-XLPE and for the supercritical processing respectively for $1 \mathrm{~kg}$ of $\mathrm{PE}$. Energy consumption for each unit process is represented as follows:

$$
E_{n}=E_{n}^{\prime}+E_{n}^{\prime \prime}
$$

$E_{n}^{\prime}$ is electric energy consumption per $1 \mathrm{~kg}$ of $\mathrm{PE}$, which was estimated equal to the voltampere(VA) per $1 \mathrm{~kg}$ of PE. Measured electric demand shown in Figure 6 was used for evaluation of that of the supercritical processing. On the other hand, electric demand for the crusher was estimated as $30 \%$ of the electric capacity of crusher which can treat $40 \mathrm{~kg} /$ hour of the Si-XLPE waste.

$E_{n}^{\prime \prime}$ is energy requirement to make the equipment in the unit process per $1 \mathrm{~kg}$ of $\mathrm{PE}$, which is represented as following equation.

$$
E_{n}^{\prime \prime}=\frac{E_{n}^{\prime \prime \prime}}{V_{n} \times D_{n} \times Y_{n} \times R_{n}}
$$

- $\quad E_{n}^{\prime \prime \prime}$ : Energy requirement to make the equipment $(\mathrm{kcal})$

- $\quad V_{n}$ : Productivity of PE (kg/hour)

- $\quad D_{n}$ : Operation time in the year (hour/year)

- $\quad Y_{n}$ : Life span of the equipment (year)

- $\quad R_{n}$ : Occupation rate of equipment for the product(-)

Equation (4) was used to estimate:

$$
E_{n}^{\prime \prime \prime}=\sum_{l} U_{l} W_{l}
$$

$W_{l}$ is weight of the part of equipment $(\mathrm{kg}) . U_{l}(\mathrm{kcal} / \mathrm{kg})$ is unit base of the materials of which part of equipment consist. Equipment used for crusher and for the supercritical treatment mainly consist of steel. So, we calculate the energy consumption for the production of the equipment as following equation instead of equation (4).

$$
E_{n}^{\prime \prime \prime}=U_{F e} W_{n}
$$

$W_{\mathrm{n}}$ is total weight of the equipment for the unit process $(\mathrm{kg}) . \mathrm{U}_{\mathrm{Fe}}$ is unit base of steal (kcal/kg).

The found energy consumption is shown in Table 6. The required energy for the recycling of $\mathrm{Si}$-XLPE was smaller than that of virgin PE. These results indicate that the recycling of SiXLPE using supercritical alcohol can save energy consumption.

Moreover, further information about the recycling process is revealed as follows. Energy required for the construction of the equipment is smaller than that of the electric energy used for the operation of the equipment. Electric energy was mainly used as the energy source for the heaters and for the motors. So, these results indicate that the heat insulation and the efficiency of the motors are important matters in saving energy rather than the size reduction of the equipment. 
The general aim of recycling is saving resources. Energy is the most fundamental resource because every human activity, including mining, requires energy. So, LCA on energy is a useful tool for the development and evaluation of the meaning of recycling technology.

\begin{tabular}{|c|c|c|c|}
\hline \multicolumn{2}{|c|}{} & Recycled PE $(\mathrm{kcal} / \mathrm{kg})$ & Virgin PE $(\mathrm{kcal} / \mathrm{kg})$ \\
\hline \multicolumn{2}{|c|}{$E_{\mathrm{MeOH}}$} & 244.4 & - \\
\hline \multicolumn{2}{|c|}{$E_{P E}$} & - & - \\
\hline \multirow{2}{*}{$E_{1}$} & $E_{1}^{\prime}$ & 0.6 & - \\
\cline { 2 - 5 } & $E_{1}^{\prime \prime}$ & 103.7 & - \\
\hline \multirow{2}{*}{$E_{2}$} & $E_{2}^{\prime}$ & 17.0 & - \\
\cline { 2 - 5 } & $E_{2}^{\prime \prime}$ & 2240.2 & 7054.0 \\
\hline \multicolumn{2}{|c|}{ Total } & 2605.9 & - \\
\hline
\end{tabular}

Table 6. Energy analysis of the recycled PE.

ECR is calculated from the data shown in table as following equation.

$$
E C R=\frac{7054.0}{2605.9}=2.71
$$

The obtained ECR is 2.71 which means that recycling of Si-XLPE is the technology that can contribute for saving energy. This example also indicates that the LCA and EPR methods are useful for evaluation of recycling technology. Moreover, these methods will be effective in the development of the recycling process to look at the final target.

\section{Conclusion}

The energy consumption for the recycling of Si-XLPE was studied. It is indicated that energy can be saved if the extruder is applied as a feeder and a reactor for the reaction in supercritical methanol. A life cycle energy assessment can give an answer to the criticism of wasting of energy because of the high pressure and temperature of supercritical methanol. Moreover, the results give us a principle in the development of a more efficient process.

\section{References}

Amano, O.(2006) "JHFC report about result of the study on total efficiency", Japan Automobile Research Institute

Amano, O.(2008) Energy after Oil Peak

Amano, O.(2010) How to live after Oil Peak

Arai, Y(2002) Supercritical Fluid, Techno System

Donella, H Meadows, Dennis L. Meadows, Jorgen Randers, and William W. Behrens III. (1972).The Limits to Growth. New York: Universe Books. ISBN 0-87663-165-0

Gunther, F, The rabbit limit,

Goto T., Ashihara S., Yamazaki T., Sugeta T., Okajima I., Sako T., Yoshihiko Iwamoto, Ishibashi M., (2011) Continuous Process for Recycling Silane Cross-linked Polyethylene Using Supercritical Alcohol and Extruders. Industrial \& Engineering Chemistry Research, 50, 5661-5666 
Goto T., Ashihara S., Yamazaki T., Watanabe K.(2006) The transactions of the Institute of Electrical Engineers of Japan. B, A publication of Power and Energy Society 126,4, 400-406

Goto T., Yamazaki T., Sugeta T., Okajima I., Iwamoto Y., Kakizaki J., Ohtake K., Sako T., Kagaku Kogaku (2005) Research on Continuous Recycling Process for Cross-linked Polyethyelne by Supercritical Alcohol. Ronbunshu Vol.31, No.6, p.411

Goto T., Yamazaki T., Sugeta T., Okajima I., Sako T., (2008) Selective Decomposition of the siloxane bond constituting element of silane-crosslinked polyethylene by supercritical alcohol, J. Applied Polymer Sci., Vol.109, p.144

Goto T., Yamazaki T., Sugeta T., Okajima I., Sugeta T., Miyoshi T., Shigenobu, H., Ohtake, K., Sako T. (2001) Recycling of Cross-linked Polyethylene Using Supercritical Fluid, Kobunsi Ronbunsyu Vol.58, No.12, p.703

Goto, T.; Amano, O.; Okajima, I.; Sako T.(2009) Evaluation Method for Production Technology using Concept of Energy Profit Ratio, Journal of Mottainai gakkai ,3,1-6

Goto, T.; Yamazaki, T. (2004) Recycling of Silane Cross-linked Polyethylene for Insulation of Cables using Supercritical Alcohol. Hitachi Cable Review, 23, 24-27

International Energy Agency(2010) World Energy Outlook 2010

ISO 14040 (2006): Environmental management - Life cycle assessment - Principles and framework, International Organisation for Standardisation (ISO), Geneve

ISO14044(2006):Environmental management-Life cycle assessment - Requirements and guidelines, International Organisation for Standardisation (ISO), Geneve

Ito, T; Tahara, H; Narita, N(2007) An outline of LCA, Sangyo Kankyo Kanri Kyoukai Co.

Kerr, R (2007) The Looming Oil Crisis. Could Arrive Uncomfortably Soon, Science, 316, 20, 351

Kitahara, S. (1969) Dissolution and Alternation of Surfaceof Silica Gel Powder in Ethanol between $150^{\circ} \mathrm{C}$ and $250^{\circ} \mathrm{C}$

Kitahara, S., Asano, T., Hirowatari, T (1970) Dissolution and Alternation of Surfaceof Silica Gel Powder in Ethanol between $150^{\circ} \mathrm{C}$ and $250^{\circ} \mathrm{C}$

M.K. Hubbert (1956) Nuclear Energy and the Fossil Fuels, Presented before the Spring Meeting of the Southern District, American Petroleum Institute, Plaza Hotel, San Antonio, Texas, March 7-8-9

Maruyama, M.(2003) Research on the Life Cycle Model of the Waste Materials from the Recycling System of Cable and Wire. JECTEC NEWS, 7, 18-23

Reuck, K.M.; Craven, R.J.B (1993) Methanol, International thermodynamic tables of the fluid state - 12, IUPAC, Blackwell Scientific Publications, London

Saito, S.,(1996) Science and Engineering of Supercritical Fluid, Sankyo Buisiness

Sako, T., Sugeta, T., Okajima, I.(1998) Countermeasure for resource and enviromental problem, 34, 31

Takeda K.(2008) Society and Economic Aspect of Polymer Recycling, the Society of Rubber Industry Japan Vol.81, p.5

Tokuda, S.; Horikawa, S.; Negishi, K.; Uesugi, K.; Hirukawa, H. (2003) Material Recycling Technology of Crosslinked Polyethylene. Furukawa Denkou Jiho, 111, 1, 90-94

Voldner, E.(2000) Crosslinked Polyethylene Scrap Can Be Recycled. Innov. Rotational Molding Year Beyond, Ohio U.S.A. 1999, 73-82.

White, C. C.; Wagenblast, J.; and Shaw, M. T.(2000) Separation Size Reduction and Processing of XLPE from Electrical Transmission and Distribution Cable. Polym. Eng. Sci., 40, 4, 863-879 


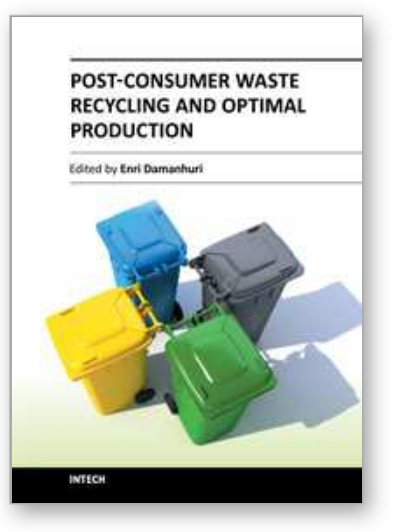

\author{
Post-Consumer Waste Recycling and Optimal Production \\ Edited by Prof. Enri Damanhuri
}

ISBN 978-953-51-0632-6

Hard cover, 294 pages

Publisher InTech

Published online 23, May, 2012

Published in print edition May, 2012

This book deals with several aspects of waste material recycling. It is divided into three sections. The first section explains the roles of stakeholders, both informal and formal sectors, in post-consumer waste activities. It also discusses waste collection programs for recycling. The second section discusses the analysis tools for recycling system. The third section focuses on the recycling process and optimal production. I hope that this book will convey both the need and means for recycling and resource conservation activities to a wide readership, at both academician and professional level, and contribute to the creation of a sound materialcycle society.

\title{
How to reference
}

In order to correctly reference this scholarly work, feel free to copy and paste the following:

Toshiharu Goto (2012). Evaluation of the Energy Consumption of Recycling Process, Post-Consumer Waste Recycling and Optimal Production, Prof. Enri Damanhuri (Ed.), ISBN: 978-953-51-0632-6, InTech, Available from: http://www.intechopen.com/books/post-consumer-waste-recycling-and-optimal-production/evaluation-ofthe-energy-consumption-of-recycling-process

\section{INTECH}

open science | open minds

\section{InTech Europe}

University Campus STeP Ri Slavka Krautzeka 83/A 51000 Rijeka, Croatia Phone: +385 (51) 770447

Fax: +385 (51) 686166 www.intechopen.com

\section{InTech China}

Unit 405, Office Block, Hotel Equatorial Shanghai No.65, Yan An Road (West), Shanghai, 200040, China 中国上海市延安西路65号上海国际贵都大饭店办公楼405单元 Phone: +86-21-62489820

Fax: +86-21-62489821 
(C) 2012 The Author(s). Licensee IntechOpen. This is an open access article distributed under the terms of the Creative Commons Attribution 3.0 License, which permits unrestricted use, distribution, and reproduction in any medium, provided the original work is properly cited. 